\title{
Educational studies in mathematics book review: editor's comment
}

\author{
Gail FitzSimons ${ }^{1}$
}

Published online: 9 July 2015

(C) Springer Science+Business Media Dordrecht 2015

I have recently received, in close succession, two reviews of the same book Mathematics and the Body: Material Entanglements in the Classroom, by Elizabeth de Freitas and Nathalie Sinclair. Judging from the reviews, this is a book which challenges many of the orthodoxies of mathematics education as it is currently constituted for many academics and practising teachers. It is clear that the book also demanded a great deal of effort on the part of the reviewers to convey their own developing understandings as well as how it might be of interest to the diversity of readers of this journal.

One review was submitted by a single author, Francesca Ferrara, who prepared a very careful and thoughtful review of the book, relating it to her research interests and recent readings. Comprising about 3000 words, her submission was of typical length for such reviews. The second review was submitted by a team of doctoral students who worked with Beth Herbel-Eisenmann, their supervisor, to prepare a much longer review essay which also incorporated reflections and questions based on lengthy discussions which were enriched by their diverse theoretical and experiential backgrounds. Both reviews are to be commended, and I encourage readers to submit both single author and collaborative reviews and feel welcome to contact me as the book review editor, particularly if they are contemplating a longer review essay.

Gail FitzSimons

gfi@unimelb.edu.au

1 University of Melbourne, Parkville, Victoria 3010, Australia 